\title{
Current state of data-based gating technology in PET imaging
}

\author{
Adam Leon Kesner
}

Received: 1 December 2010 /Accepted: 17 December 2010/Published online: 29 January 2011

(C) Springer-Verlag 2011

Dear Sir,

I would like to add a comment to a recent article published in EJNMMI entitled "Detection of respiratory tumour motion using intrinsic list mode-driven gating in positron emission tomography" by Büther et al. [1]. This article makes a significant contribution to an area that needs development. I would like to point out, however, that there exists additional work that has been presented on data-based gating algorithms in PET, as this is relevant to the context of the article and the future aims of the community.

Previous publications and presentations have laid the groundwork for the geometric sensitivity gating method [2] and have offered alternative approaches to data-based gating [3-8]. These approaches do not suffer from some of the negative issues mentioned in the article: dependence on lesion location, necessity for a definable region of high uptake, and loss of truncated information. Nor do they require operator interaction for lesion delineation or frequency window determination. In addition, our recent study directly compared the geometric sensitivity gating method (the automated method used by Büther et al.) with more advanced automated algorithms, and found substantial differences in quality [7].

Büther et al. did produce good science that is laying important groundwork for the application of data-based gating, and the accompanying references might add to the current understanding of this young and promising subfield.

\section{References}

1. Büther F, Ernst I, Dawood M, Kraxner P, Schafers M, Schober O, et al. Detection of respiratory tumour motion using intrinsic list modedriven gating in positron emission tomography. Eur J Nucl Med Mol Imaging. 2010;37:2315-27. doi:10.1007/s00259-010-1533-y.

2. He J, O'Keefe GJ, Gong SJ, Jones G, Saunder T, Scott AM, et al. A novel method for respiratory motion gated with geometric sensitivity of the scanner in 3D PET. IEEE Trans Nucl Sci. 2008;55:2557-65.

3. Kesner AL, Bundschuh RA, Detorie NC, Dahlbom M, Czernin J, Silverman DHS. Respiratory gated PET derived from raw PET data. Nuclear Science Symposium Conference Record, 2007 NSS '07 IEEE. 2007;4:2686-91.

4. Kesner AL, Dahlbom M, Czernin J, Silverman DH. Respiratory gated PET based on time activity curve analysis. J Nucl Med 2007;48 (Suppl 2):416P.

5. Kesner AL, Bundschuh RA, Detorie NC, Dahlbom M, Ziegler SI, Czernin J, et al. Respiratory gated PET derived in a fully automated manner from raw PET data. IEEE Trans Nucl Sci. 2009;56:677-86.

6. Kesner AL. A new data based method for acquiring respiratory signal from raw PET data to be used for respiratory gating. Radiother Oncol. 2010 (Suppl 1);94.

7. Kesner AL, Kuntner C. A new fast and fully automated software based algorithm for extracting respiratory signal from raw PET data and its comparison to other methods. Med Phys. 2010;37:5550-59.

8. Dineley J. Fully automated gating: a new era for PET? Medicalphysicsweb; 2010. http://medicalphysicsweb.org/cws/article/ research $/ 44273$

A. L. Kesner $(\square)$

Dosimetry and Medical Radiation Physics (DMRP) Section,

Division of Human Health,

International Atomic Energy Agency (IAEA),

P.O Box 100, Wagramer Strasse 5,

A-1400, Vienna, Austria

e-mail: adam.kesner@fulbrightmail.org 